\title{
Enhancement of heat transfer of double tube heat exchanger with inner twisted spiral tube
}

\author{
Abdalla Gomaa, Mahmoud Abdelmagied, Yasmin Mhrous \\ Department of Refrigeration and Air Conditioning Technology, Faculty of Technology and \\ Education, Helwan University, Cairo-Egypt.
}

\begin{abstract}
:
Heat transfer and fluid flow characteristics for twisted spiral tubes with different pitch and depth have been investigated experimentally with respect of smooth tube as a particular reference. The effects of the twisted spiral pitch $(S)$ and depth $(H)$ on the thermal performance of a twisted spiral tubes heat exchanger are investigated. The effects of inner twisted spiral tube pitch, depth, Reynolds number and flow arrangement were the main points of interest. Three twisted spiral tube with different pitch $(S)$ and three twisted spiral tube at different depth $(H)$ are examined in this study. The Reynolds number ranged from 5000 to 50,000 and from 1400 to 10400 for both inner tube and outer tube sides, respectively, corresponding to water mass flow rates ranged from 0.03 to $0.3 \mathrm{~kg} / \mathrm{s}$. The results showed that, both Nusselt number and friction factor increased with all values of pitches $(S)$ above that of the smooth tube. The Nusselt number of cases of pitches of 3.9, 5.2 and $8.2 \mathrm{~mm}$ is $33.6 \%, 21.4 \%$ and $7.6 \%$ higher than the smooth tube on expense of increasing the friction factor by $23.2 \%, 18.4 \%$ and $4.6 \%$, respectively. Also, the Nusselt number and friction factor increased with all cases of depth $(H)$ above that of the smooth tube. The Nusselt number of cases of depths $1.15,1.1$ and $0.6 \mathrm{~mm}$ is respectively $34.4 \%, 27.8 \%$ and $10 \%$, respectively, higher than that of the smooth tube. Also, the friction factor for the twisted spiral depths $(H)$ of $1.15,1.1$ amd $0.6 \mathrm{~mm}$ is about $22.8 \%, 18.4 \%$ and $2.3 \%$ higher than that of the smooth tube, respectively.
\end{abstract}

Keywords: Enhancement of heat transfer, Heat exchanger, twisted spiral tubes. 


\begin{tabular}{|c|c|c|c|}
\hline \multicolumn{4}{|c|}{ Nomenclature } \\
\hline$A$ & area $\bullet \mathrm{m}^{2}$ & $V$ & Velocity $\cdot \mathrm{m} \cdot \mathrm{s}^{-1}$ \\
\hline$C_{p}$ & specific heat $\cdot \mathrm{kJ} \cdot \mathrm{kg}^{-1} \cdot{ }^{\circ} \mathrm{C}^{-1}$ & \multicolumn{2}{|c|}{ Greek symbol } \\
\hline$D$ & Diameter $\cdot \mathrm{m}$ & $\varepsilon$ & Effectiveness \\
\hline$D_{h y, o}$ & hydraulic diameter , m & $\mu$ & dynamic viscosity $\bullet \mathrm{kg} \cdot \mathrm{m}^{-1} \cdot \mathrm{s}^{-1}$ \\
\hline$F$ & friction factor & $\rho$ & Density $\mathbf{k g} \cdot \mathrm{m}^{-3}$ \\
\hline$H$ & Depth of twisted spiral & \multicolumn{2}{|c|}{ Subscripts } \\
\hline$h$ & convective heat transfer coefficient, $\mathrm{W} \cdot \mathrm{m}^{-2} \cdot{ }^{\circ} \mathrm{C}^{-}$ & $-1 \quad a v g$ & average \\
\hline$K$ & fluid thermal conductivity $6 \mathrm{~W} \cdot \mathrm{m}^{-1} \cdot{ }^{\circ} \mathrm{C}^{-1}$ & $b$ & bulk \\
\hline$L$ & Length $6 \mathrm{~m}$ & $c$ & cold fluid \\
\hline$\dot{m}$ & mass flow rate $\cdot \mathrm{kg} \cdot \mathrm{s}^{-1}$ & $h$ & hot fluid \\
\hline $\mathrm{Nu}$ & Nusselt number & $i$ & Inlet \\
\hline$\Delta P$ & pressure drop $، \mathrm{~Pa}$ & LMTD & log mean temperature difference \\
\hline $\operatorname{Pr}$ & Prandtl number $\triangleleft(\mu \cdot \mathrm{C} / \mathrm{k})$ & $\min$ & minimum \\
\hline$Q$ & heat transfer rate $\cdot \mathrm{W}$ & $o$ & Outlet \\
\hline $\operatorname{Re}$ & Reynolds number & & \\
\hline$S$ & pitch of twisted spiral & & \\
\hline$T$ & Temperature $6^{\circ} \mathrm{C}$ & & \\
\hline$U_{o}$ & $\begin{array}{l}\text { overall heat transfer } \\
\text { coefficient } ` \mathrm{~W} \cdot \mathrm{m}^{-2} \cdot{ }^{\circ} \mathrm{C}-{ }^{1}\end{array}$ & & \\
\hline
\end{tabular}

\section{Introduction.}

Double twisted spiral tubes heat exchanger are used in many kinds of industries such as chemistry, engineering fields such as air conditioning and refrigeration, power plants, food production plants such as dairy pasteurization. There are three ways to enhance the heat transfer 
of heat exchangers, the first method is the positive method, in which external forces are used to enhance the heat transfer, the second method is the negative method, in which some modifications are made to the surfaces of the heat exchanger tubes or some additives are included in the operating fluids such as Nano fluids. The third method, which is a method that combines the negative and the positive method, is called the combined method. There are many experimental and numerical studies that have studied the effect of different methods to enhance heat transfer in heat exchangers. Heat transfer enhancement in two-start spirally corrugated tube had been studied by Kareem et al. [1], The study designed to the determination of the thermal performance plain and corrugated tubes. The improvement of heat transfer ranged from $21.6 \%-$ $60.5 \%$ and friction factor increased from 19.2-36.4\%. Enhancement of heat transfer in six-start spirally corrugated tubes was studied by Balla [2], a theoretical and experimental study of smooth and corrugated tubes by studying Nusselt number and friction coefficients. The results showed that, a marked increase in heat transfer for corrugated tubes more than smooth tubes about (2.4 -3.7) times, and friction coefficient ranged from 1.7 to 2.4 times than smooth tubes. Tang et al. [3], achieved an experimental and numerical study to study the effect of turbulent flow and the heat transfer the performance of twisted tri-lobed tube (TTT) and twisted oval tube (TOT). The results summarized that, (TTT) tube was better than (TOT), the heat performance improved by about $5.4 \%$, while the friction coefficient increased by about $8.4 \%$. The numerical results showed that the highest rate of friction coefficient and thermal performance when the pitch was less, the numerical study also showed that twisted tube with right-left hand rotation is better heat transfer performance than the tube with right hand rotation. Kareem et al. [4] analyzed experimentally and numerically the performance of three-start spirally corrugated tube. The results founded that, the spiral corrugations can improve the heat transfer in the range of (2.4-3.7) times of smooth tube. The friction factor increased about (1.7-2.4) times of the smooth tube. Jin et al. [5] studied the effects of pitch and depth of corrugated tube. The result showed that the increasing of pitch lead to decrease the heat transfer and Nusselt number gradually. The heat transfer increases about 1.05-1.33 times than the smooth tube. 3D numerical study on shell side heat transfer and flow characteristics of rod-baffle heat exchangers with spirally corrugated tubes was presented by Liu et al. [6], the results showed that the heat transfer rates for corrugated tubes (one-start, two-start, three-start, and four-start) are (104.6\% -105.4\%$106.7 \%$ and $109.6 \%$ ) respectively. A spirally corrugated tubes is 1.2 times that of rod-baffle heat 
exchangers. Numerical study on flow characteristics and heat transfer enhancement of oscillatory flow in a spirally corrugated tube was investigated by Xin et al. [7], the study present the effect of changing tube shape from smooth to two-start spirally corrugated, The results showed an increase in heat transfer rates for the corrugated tube compared to the smooth tube. Enhanced tubing thermal performance for innovative system was studied by Kalendar et al. [8]. An experimental study to replace smooth tube with corrugated tube to enhance the heat transfer in a desalination plant was present. The results showed that the value of the heat transfer coefficient of the corrugated tube is higher than the smooth tube. Rozzi et al. [9] drive an experimental study to enhance heat transfer and pressure loss of heat exchangers by using corrugated and smooth tubes. The results showed that the heat transfer rate was higher for corrugated tubes but the pressure was decreased. An experimental heat-transfer study for a heat-recovery unit made of corrugated tubes was investigated by Poredos et al. [10], the study present the effect of the engineering properties of corrugated pipes of a double tube heat exchange, the results presented that, the highest heat transfer rate occurred at the corrugation ratio was less than 1.65 , the rate of pressure drop was (3- 3.5) times from the smooth tube. $\mathrm{Xu}$ et al. [11], were investigated experimental and numerical the heat transfer of Thermion heat transfer fluid in an internally four-head ribbed tube. The results showed that the heat enhancement at rate of (1.1-1.35) times from the smooth tube. The friction factor increased (1.3-1.5) times, and the pressure drop for the ribbed tubes increased more than the smooth. Jianfeng et al. [12] presented an experimental study for the effect of corrugated tubes and nitrate molten salt on the performance of heat transfer by using electrical energy, the results showed the increasing depth enhanced the heat transfer opposite the pitch increasing. Khoeini et al. [13] showed the heat transfer coefficient of condensation for R-134a fluid inside corrugated tubes with different inclinations. The largest condensation temperature coefficient was obtained at $\alpha=30^{\circ}$ which was 1.41 times greater than $\alpha$ $=-90^{\circ}$. The highest heat transfer rate was given at all mass velocities at $\alpha=30^{\circ}$. Heat transfer and friction characteristics of spirally corrugated tubes for outer ammonia condensation were studied experimentally by Seara and Francisco [14]. The results were compared with smooth tubes. The rate of heat transfer improvement factor ranged from 2.11 to 2.53, friction factors were 4 - 5 times of smooth tubes. The thermal performance of corrugated pipes is 1.27 times than of smooth tubes. Turbulent heat transfer enhancement in a heat exchanger using helically corrugated tube was studied experimentally by Pethkool et al. [15]. The result showed that, the 
maximum heat transfer was 2.33 at $S / D_{h}=0.27$ and $H / D_{h}=0.06$. Nusselt number and friction factor was 3.01 and 2.14 times than the smooth tube at low Reynolds number. Hence, the present study aims to study the thermal performance of a twisted spiral tubes at different geometry parameters of the heat exchanger with a particular reference of smooth tube. Three twisted spiral tube at different $(S)$, and three twisted spiral tube at different $(H)$ were manufactured, designed, and tested. The main concern of the study focused on the enhancement of the heat transfer characteristics and effectiveness of such heat exchanger.

\section{Experimental apparatus}

The experimental test rig consists of three main circuits which are the chilled water closed loop circuit, the closed-loop of hot water circuit, and the test specimen circuit as illustrated in Fig. 1. The cold water produced from a chilled water system which consists of a chilled water refrigeration circuit, an insulated tank of $0.15 \mathrm{~m}^{3}$ capacity, $2 \mathrm{HP}$ centrifugal pump, a ball valve, and a rotameter. On the other side, The hot water circuit which consists of an insulated tank of $0.25 \mathrm{~m}^{3}$ capacity, four heaters $1.5 \mathrm{~kW}$ each, $1 \mathrm{HP}$ centrifugal pump, and a rotameter (0 to18 $\mathrm{Lit} / \mathrm{min}$ ) to produce the hot water. The temperature inside the hot water tank was maintained constant at $60 \pm 0.5^{\circ} \mathrm{C}$. The test specimens of the double-twisted spiral tube consist of two concentric copper tubes. The outer diameter of the external tube was $22.2 \mathrm{~mm}(7 / 8 \mathrm{inch})$ and the outer diameter of the internal tube $15.8 \mathrm{~mm}$. Geometrical parameters details of the twisted spiral tubes were showed in Fig.2. Details of the dimensions of the physical tubes were given in Table 1. The outer tube of the heat exchanger was thermally insulated by rubber foam pipe insulation $\left(\mathrm{k}=0.031 \mathrm{~W} \cdot \mathrm{m}^{-1} \cdot \mathrm{K}^{-1}\right)$.

Table 1 Geometric parameters of the inner twisted spiral tube.

\begin{tabular}{cccccc}
\hline Specimen No & $\mathrm{S}(\mathrm{mm})$ & $\mathrm{H}(\mathrm{mm})$ & $\mathrm{D}_{\mathrm{i}, \mathrm{o}}(\mathrm{mm})$ & $\mathrm{D}_{\mathrm{o}, \mathrm{o}}(\mathrm{mm})$ & $\mathrm{L}(\mathrm{mm})$ \\
\hline 1 & 3.9 & 1.1 & 15.8 & 22.2 & 100 \\
2 & 5.2 & 1.1 & 15.8 & 22.2 & 100 \\
3 & 8.2 & 1.1 & 15.8 & 22.2 & 100 \\
4 & 5.2 & 0.6 & 15.8 & 22.2 & 100 \\
5 & 5.2 & 1.15 & 15.8 & 22.2 & 100 \\
6 & - & - & 15.8 & 22.2 & 100 \\
\hline
\end{tabular}

\section{Uncertainty analysis.}

The implication of the experimental error specifies the error of the measuring quantities. For 
the different calculated parameters, the uncertainty analysis was determined according to
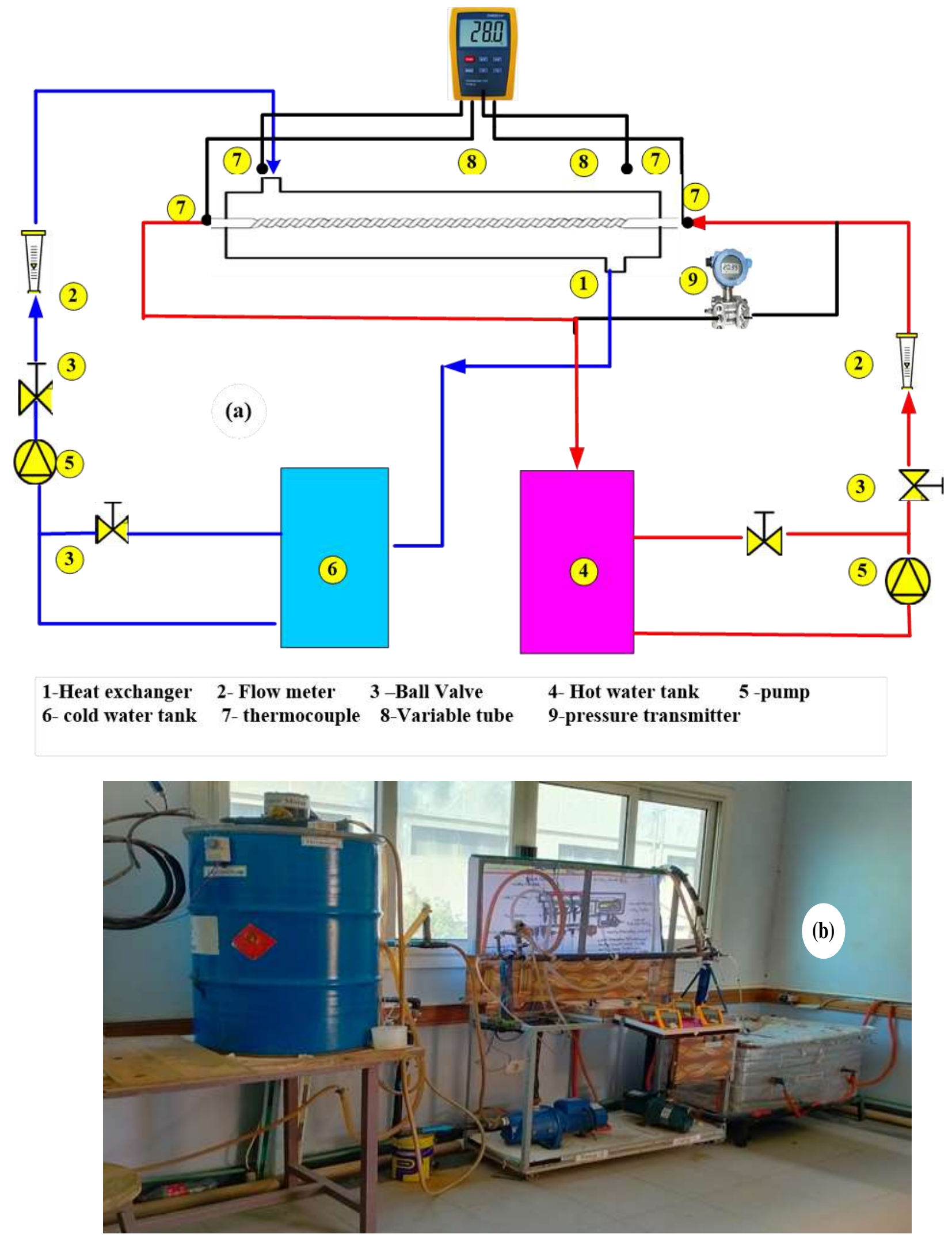
Fig.1. Experimental test rig, (a) Schematic diagram, and (b) photograph view.
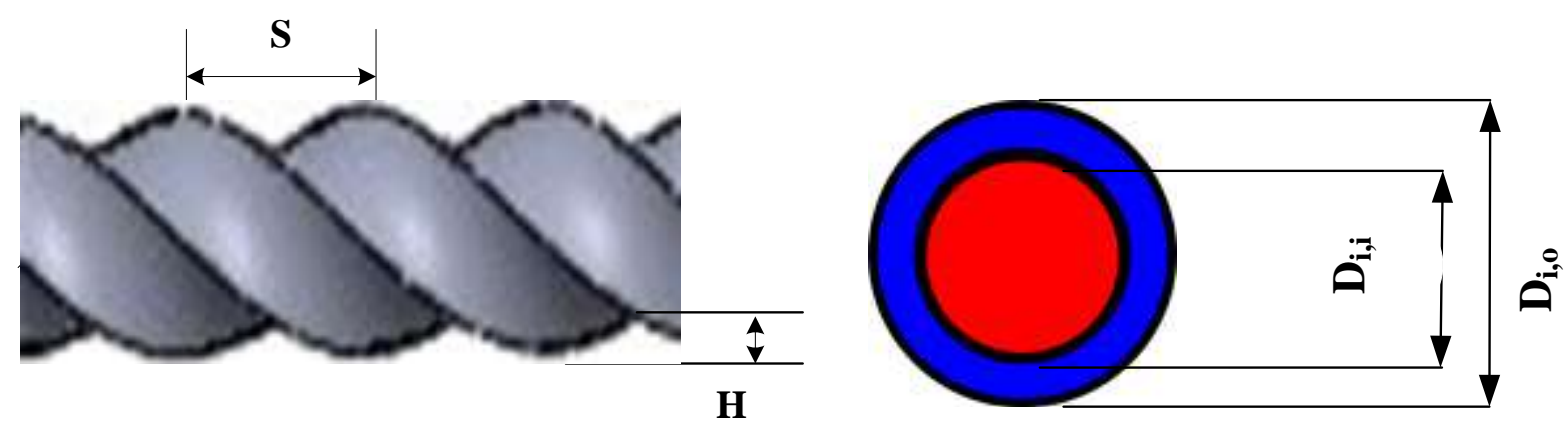

Fig.2. Schematic diagram of the of twisted spiral tube

Holman [16]. The measuring device's uncertainty and accuracy were given in Table 2.

Table 2 The range, accuracy and uncertainties of measuring devices.

\begin{tabular}{lccc}
\hline Instruments & Range & Accuracy (\%) & Uncertainty (\%) \\
\hline Rotameter, kg.s ${ }^{-1}$ & & & \pm 0.17 \\
Thermocouple K-type, ${ }^{\circ} \mathrm{C}$ & $-200-1200$ & \pm 0.1 & \pm 0.16 \\
Digital differential pressure transmitter, $\mathrm{kPa}$ & $0.5-500$ & \pm 0.5 & \pm 01.16 \\
Reynolds number & $5000-50000$ & - & \pm 2.8 \\
Friction factor & - & - & \pm 4.6 \\
Nusselt number & - & - & \pm 4.6 \\
Effectiveness & - & - & \pm 5.4 \\
\hline
\end{tabular}

\section{Data reduction}

The data reduction of the measured results is summarized in the following procedures.

The heat transferred to the cold water in the test section $\left(Q_{c}\right)$ can be calculated as:

$$
Q_{c}=m_{c}^{\square} C p_{c}\left(T_{c, o}-T_{c, i}\right)
$$

Heat transferred from the hot water $\left(Q_{h}\right)$ can be calculated as:-.

$$
Q_{h}=m_{h}^{\square} C p_{h}\left(T_{h, o}-T_{h, i}\right)
$$

At zero heat loss, the amount of heat transfer in cold side equal to the amount of heat transfer hot side. In order to minimize the error in calculation, the average heat transfer rate, $Q_{a v e}$, is used in calculation of the overall heat transfer coefficient in which the average heat transfer $Q_{a v g}$ as follow: 


$$
Q_{\text {avg }}=0.5\left(Q_{c}+Q_{h}\right)
$$

The overall heat transfer coefficient, $U_{o}$, was obtained from:

$$
U_{o}=\frac{Q_{\text {avg }}}{A \Delta T_{L M T D}}
$$

Where $\Delta T_{L M T D}$ is the logarithmic mean temperature difference

$$
\Delta T_{L M T D}=\frac{\left(T_{h, o}-T_{c, o}\right)-\left(T_{h, i}-T_{c, i}\right)}{\operatorname{Ln}\left[\left(T_{h, o}-T_{c, o}\right) /\left(T_{h, i}-T_{c, i}\right)\right]}
$$

Nusselt number of the inner tube was calculated from Naphon et al. [17].The correlation for Nusselt number based on Reynolds number, Prandtl number, pitch and depth of twisted spiral expressed as:

$$
N u_{h}=44.26(\mathrm{H} / \mathrm{D})^{0.89}(\mathrm{~S} / \mathrm{D})^{-0.96}\left(\operatorname{Re}_{h}-1500\right)^{0.27} \operatorname{Pr}_{h}^{-0.26}
$$

The correlation for Nusselt number for smooth tube was calculated from Naphon et al. [17]:

$$
N u_{h}=1.84\left(\operatorname{Re}_{h}-1500\right)^{0.32} \operatorname{Pr}_{h}^{0.07}
$$

The Reynolds number of the hot water flow inside the tube is given by

$$
\operatorname{Re}=\frac{\rho V D}{\mu}
$$

The annulus heat transfer coefficient, $h_{o}$, of double twisted spiral tube heat exchanger was determined from the overall heat transfer coefficient relationship:

$$
\frac{1}{U_{o}}=\frac{A_{o}}{A_{i} h_{i}}+\frac{A_{o} \ln \left(D_{o} / D_{i}\right)}{2 \pi k L}+\frac{1}{h_{o}}
$$

The Nusselt number can be calculated as:

$$
N u_{o}=\frac{h_{o} D_{h y, o}}{k_{o}}
$$

The friction factor, $f$, can be calculated

$$
f=\frac{2 \Delta p D}{L \rho V^{2}}
$$

To calculate the effectiveness of the heat exchanger the following equation is used. 
$\varepsilon=\frac{Q_{a v g}}{\left(m^{\square} c p\right)_{\text {min }}\left(T_{h, i}-T_{c, i}\right)}$

\section{Results and discussion.}

The set of experiments involving one smooth tube and five twisted spiral tubes at various pitch and depth. Preliminary tests are first conducted on the smooth tube. Secondly, experiments are conducted on the twisted spiral tube with different pitch and different depth. The thermo fluid performance criterion of the heat exchanger with double-twisted spiral tube was presented in the form; Nusselt number, overall heat transfer coefficient, friction factor and Pressure drop. This criterion is demonstrated at different pitch, depth, and flow configurations.

\subsection{Effect of flow arrangements.}

The effect of the parallel and counters flow arrangement on the Nusselt number $N u$ was illustrated in the Fig.3. These results were shown for test specimen with twisted spiral pitch of $5.2 \mathrm{~mm}$ and twisted spiral depth $1.1 \mathrm{~mm}$ as a sample of test specimens. The Nusselt number $\mathrm{Nu}$ versus $R e$ for same cold water $R e_{c}$ of 9000 , the Nusselt number $N u$ for counter flow was higher than that of parallel flow by $16 \%$. This can be attributed to increasing the water temperature difference $T_{L M T D}$ between the inner annulus cold water and the hot water in the inner tube in counter flow pattern among other flow patterns. This increase leads to increase the heat transfer rate and consequently increasing $\mathrm{Nu}$ occurred.

The effect of the parallel and counter flow arrangement on the overall heat transfer coefficient and heat transfer was illustrated in the Fig.4. These results were shown for test specimen with twisted spiral pitch of $5.2 \mathrm{~mm}$ and twisted spiral depth $1.1 \mathrm{~mm}$ as a sample of test specimens. For the same cold water mass flow rate of $0.166 \mathrm{~kg} / \mathrm{s}$ and the Reynolds number of 9000 , the overall heat transfer coefficient for counter flow was higher than that of parallel flow by $8.7 \%$,on other side. 


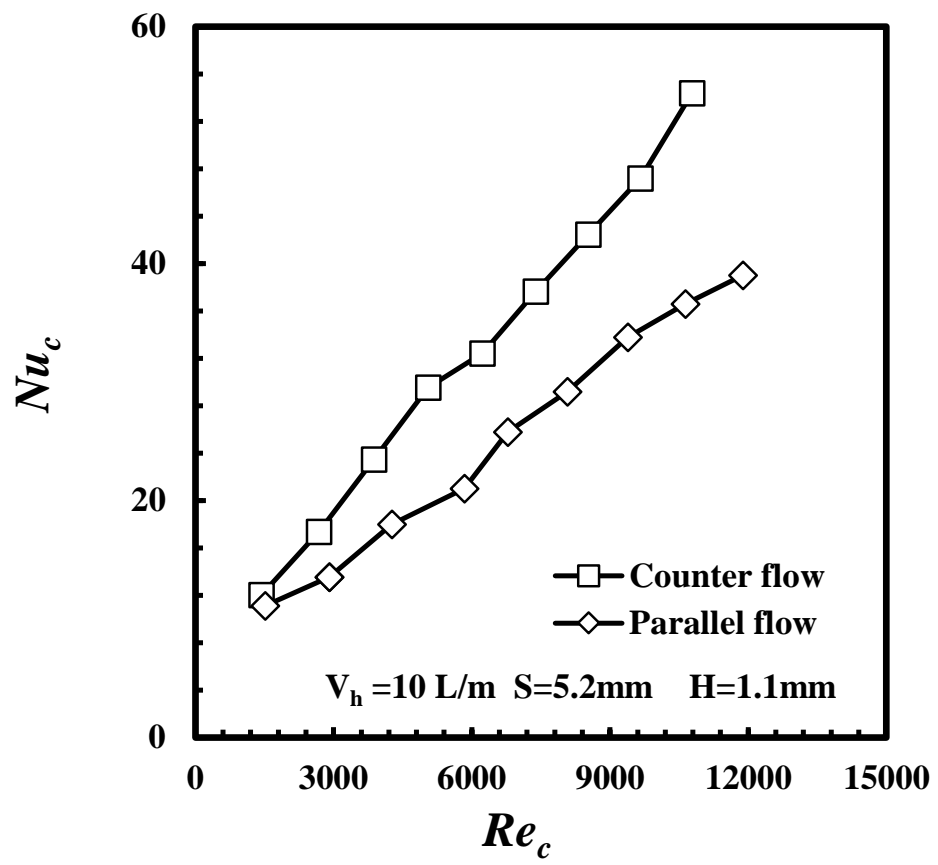

Fig. 3.Variation of Nusselt Number with Reynolds

Number of twisted spiral tube at $S=5.2$ and $H=1.1 \mathrm{~mm}$

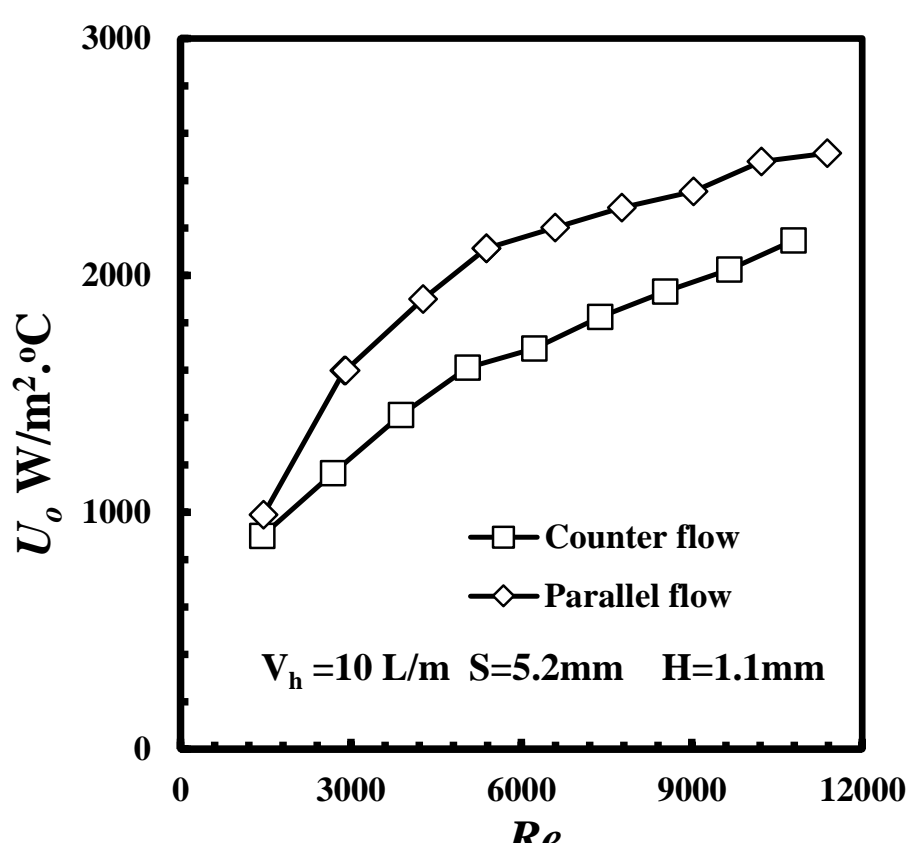

Fig. 4.Variation of overall heat transfer coefficient with Reynolds Number of twisted spiral tube at $S=5.2$ and $H=1.1 \mathrm{~mm}$

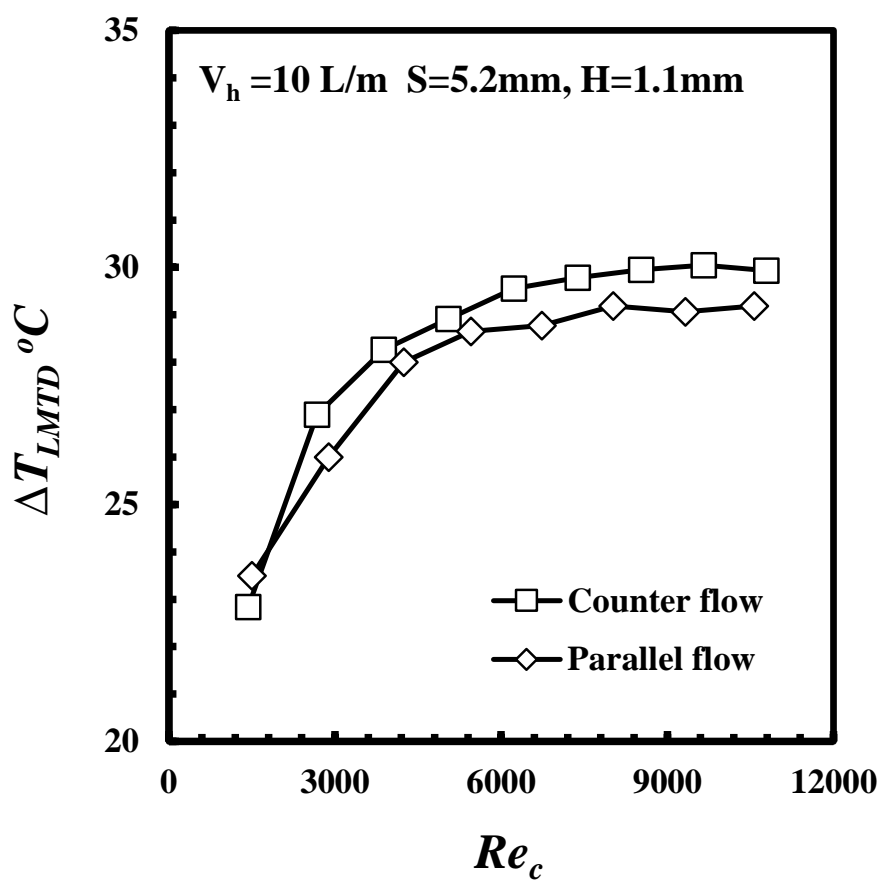

Fig. 6.Variation of $\Delta T_{L M T D}$ with Reynolds Number of twisted spiral tube at $S=5.2$ and $H=1.1 \mathrm{~mm}$
Fig.5.Variation of friction factor with Reynolds Number of twisted spiral tube at $S=5.2$ and $H=1.1 \mathrm{~mm}$ 
The friction factor $f$ versus Reynolds number $R e$ for a pitch of $5.2 \mathrm{~mm}$ was illustrated in Fig.5. It can be noticed that the friction factor $f$ decrease with $R e$. For the $R e_{c}$ number of 9000 , friction factor $f_{c}$ for counter flow was the same value of that of the parallel flow.

The logarithmic means temperature difference $\Delta T_{L M T D}$ versus Reynolds number, $R e$ for a pitch of $5.2 \mathrm{~mm}$ was illustrated in Fig.6. It can be noticed that, the logarithmic means temperature difference increase with $R e$. For the $R e_{c}$ number of 9000, $\Delta T_{L M T D}$ for counter flow was higher than that of the parallel flow by $6.7 \%$. For the counter flow pattern the cold fluid enters the heat exchanger at the exit of the hot fluid this allow to exchange more heat between two fluids. For this reason, the change in the temperature difference is less than the parallel-flow.

\subsection{Effect of twisted spiral pitch.}

Figure.7. illustrates the relation of cold water Nusselt number against Reynolds number of the smooth tube and twisted spiral tube at different pitches $(S)$ and constant depth $(H)$. $N u$ versus $R e$ for the cold water mass flow rate $0.166 \mathrm{~kg} / \mathrm{s}$, from this figure, it is apparent that Nusselt number $N u$ increases with the decrease of pitch $(S)$. It is note that at $R e=9000$, the $N u$ increases by $33.6 \%, 21.7 \%$, and $7.6 \%$ at $S=3.9, S=5.2$ and $S=8.2$, respectively, in comparison with the results obtained in the case of the smooth tube at the same conditions. This means that the Nusselt number $N u$ is inversely proportional with $S$ at constant $H$. Also, it is seen that at constant $S$ and same $H$ the $\mathrm{Nu}$ increases with the increase of Reynolds number. As the twisted spiral pitch reduced this leads to increasing the corrugations in the fluid flow, which increases heat transfer surface area and the fluid vortices, the flow becomes turbulent, this makes the boundary layer thickness decrease and improved mixing of fluid flow. This can be attributed to increasing water temperature difference $T_{L M T D}$ between the inner annulus cold water and the hot water. This increase leads to increase the heat transfer rate and consequently increasing $\mathrm{Nu}$ occurred.

Figure.8. illustrates the relation of the overall heat transfer coefficient with $R e$ of the smooth tube and twisted spiral tube at different pitches $(S)$ and constant depth $(H)$. From this figure, it is apparent that the overall heat transfer coefficient increases with the increase of pitches $(S)$ while decreases compared to smooth tube. It is note that at $R e=9000$, the overall heat transfer coefficient decreases by $23.5 \%, 39.4 \%$, and $51.5 \%$ at $S=3.9, S=5.2$ and $S=8.2$, respectively, in comparison with the results obtained in the case of the smooth tube at the same conditions. This is because the twisted spiral pitch has a significant effect on the mixing of the fluid in the 


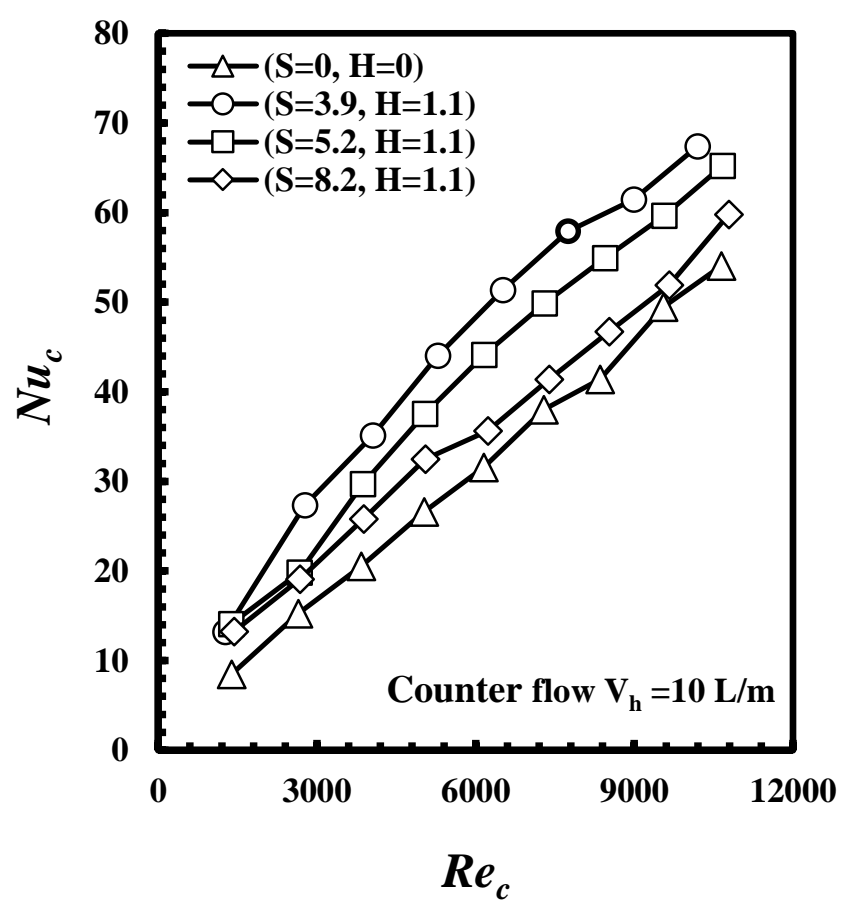

Fig.7.Variation of Nusselt Number with Reynolds Number of twisted spiral tube at different pitches

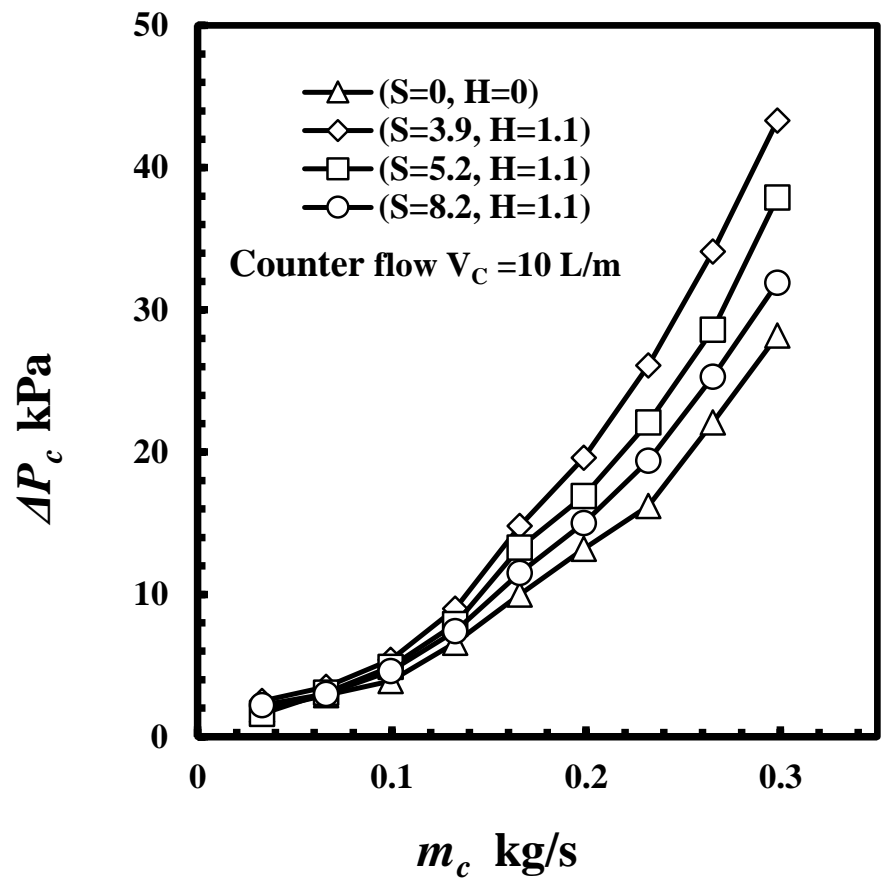

Fig.9. Variation of pressure drop with Reynolds Number of twisted spiral tube at different pitches

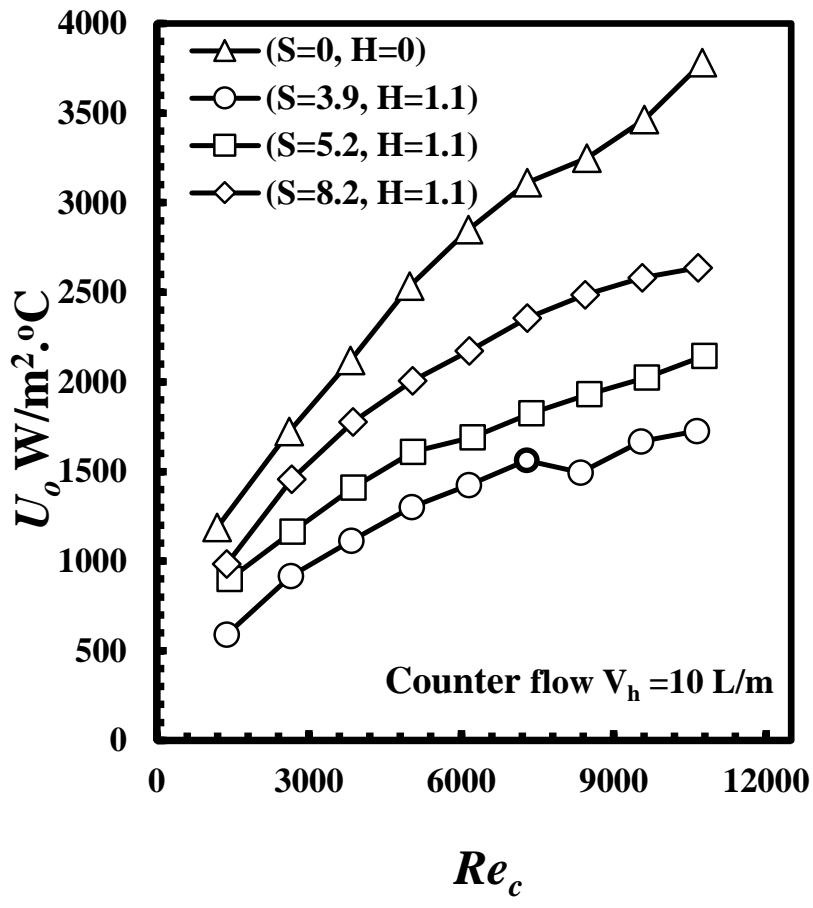

Fig.8.Variation of overall heat transfer coefficient with Reynolds Number of twisted spiral tube at different pitches

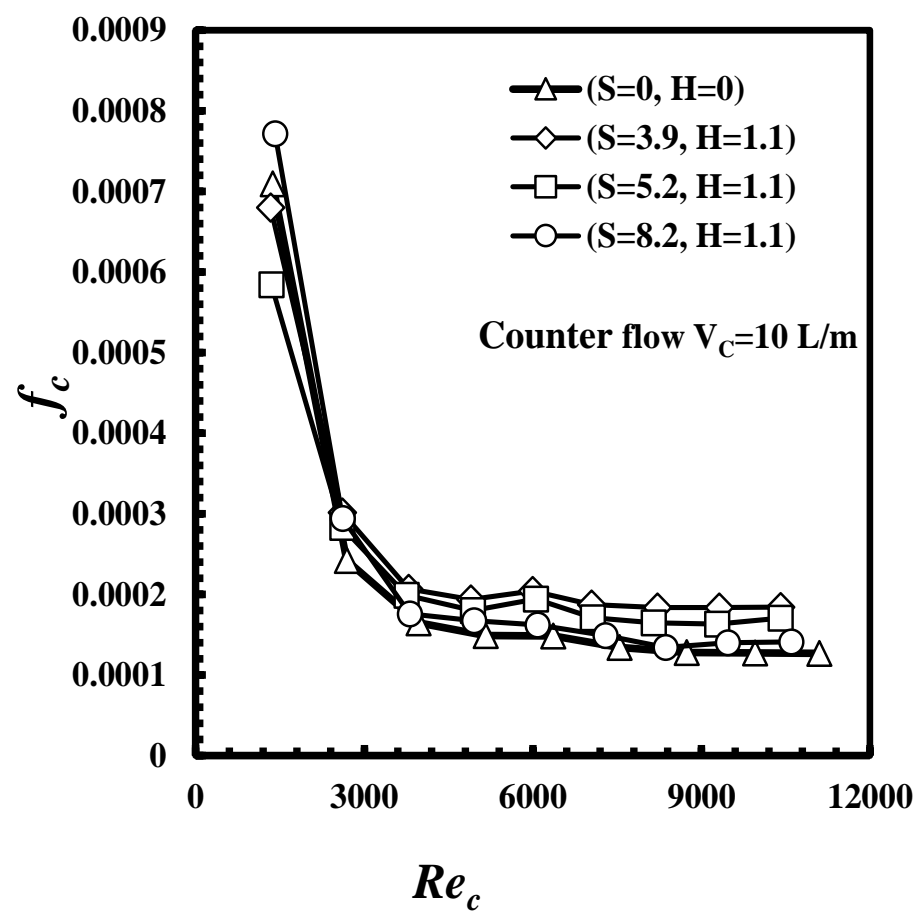

Fig.10.Variation of friction factor with Reynolds Number of twisted spiral tube at different pitches 
boundary layer and increasing the turbulent intensity of the fluid flow this increase leads to increase the heat transfer rate. On the other hand, and according to Eq. 4 while the twisted spiral tube pitch decreases the heat transfer surface area increased and the log mean temperature difference and heat transfer rate increased compared to smooth tube but the increase in heat transfer rate is less than the increase in heat transfer surface area. This demonstrate why the overall heat transfer coefficient for smooth tube is higher than twisted spiral tubes.

Figure.9. illustrates the relation of pressure drop $\Delta P$ for cold water with $m_{c}$ of the smooth tube and twisted spiral tube at different pitches $(S)$ and constant depth $(H)$. From this figure, it is apparent that pressure drop $\Delta P$ increases with the decrease of pitch $(S)$. It is note that at $m_{c}$ $=0.23 \mathrm{~kg} / \mathrm{s}$, the pressure drop $\Delta P$ increases by $61.1 \%, 36.4 \%$, and $19.7 \%$ at $S=3.9, S=5.2$ and $S=8.2$, respectively, higher than the results obtained in the case of the smooth tube at the same conditions. Owning to flow swirls increase along surfaces of the tube, which causes the turbulent flow, the turbulent flow lead to the increase the pressure drop.

Figure.10. shows the variation of friction factor $f_{c}$ versus $R e_{c}$ for various pitches of twisted spiral tube $S$ and depth H. It is observed from Fig.9 that the coefficient of friction $f$ decreases for all the geometries of pitch $S$ with the increase of $R_{c}$ at a constant depth $H=1.1 \mathrm{~mm}$ and all of them are greater than that of the smooth tube. For the same $R e_{c}$ of 9000 the friction factor of the twisted spiral tube pitches of $S=3.9 \mathrm{~mm}, 5.2$ and 8.2 are higher than the value of $f_{c}$ for smooth tube by $23.2 \%, 18.4 \%$ and $4.7 \%$, respectively. While the tube corrugation increases along surfaces of the tube, this cause more turbulence of flow. The turbulence lead to the increase the pressure loss.

\subsection{Effect of twisted spiral depth.}

Figure.11. illustrates the relation of cold water Nusselt Number $\mathrm{Nu}$ with $\mathrm{Re}$ of the smooth tube and twisted spiral tube at different depth $(H)$ and constant pitch $(S)$. From this figure, it is apparent that $N u_{c}$ increases with the increase of $(H)$. It is note that at $R e=9000$, the $N u$ increases by $34.4 \%, 27.8 \%$, and $10 \%$ at $H=0.6,1.1$ and $1.15 \mathrm{~mm}$, respectively, in comparison with the results obtained in the case of the smooth tube at the same conditions. Also, it is seen that at a constant pitch $S$ the $N u$ increases with the increase of Reynolds number for all cases. As the twisted spiral depth increasing the turbulent flow increases due to corrugation increases, this decreases the boundary layer thickness and improved mixing of fluid flow and consequently 
increasing water temperature difference $\mathrm{T}_{L M T D}$ between the inner annulus cold water and the hot water. This increase leads to increase the increase heat transfer rate and consequently increasing $\mathrm{Nu}$ occurred.

Figure.12. illustrates the relation of the overall heat transfer coefficient with $R e$ of the smooth tube and twisted spiral tube at different depths $(H)$ and constant pitch $(S)$. From this figure, it is apparent that the overall heat transfer coefficient increases with the increase of depth $(H)$ for all cases but this increase is less than the values of smooth tube for the same case. It is note that at $R e_{c}=9000$, the overall heat transfer coefficient decreases by $34.8 \%, 39.4 \%$, and $48.5 \%$ at $\mathrm{H}=$ $1.15,1.1$ and $0.6 \mathrm{~mm}$, respectively, in comparison with the results obtained in the case of the smooth tube at the same conditions. This is because the twisted spiral depth has a significant effect on the fluid turbulence. As the twisted spiral tube depth increases this increase leads to increase the fluid flow resistance, this lead to increase the heat transfer surface area and heat transfer rate.

Figure.13. illustrates the relation of pressure drop $\Delta P_{c}$ with $m_{c}$ of the smooth tube and twisted spiral tube at different depths $(H)$ and constant pitch $(S)$. From this figure, it is apparent that $\Delta P_{c}$ increases with the increase of depth $(H)$. It is note that at $m_{c}$ of $0.23 \mathrm{~kg} / \mathrm{s}$ the pressure drop $\Delta P_{c}$ increases by $52.4 \%, 19.7 \%$, and $0.6 \%$ at $H$ of $1.15,1.1$ and $0.6 \mathrm{~mm}$, respectively, in comparison with the results obtained in the case of the smooth tube at the same conditions. Owning to the twisted spiral tube depth increase, the flow resistance increases along surfaces of the tube, which causes more turbulence flow, and increase the pressure drop.

Figure.14. shows the variation of friction factor $f_{c}$ versus $R e_{c}$ for various depth of twisted spiral tube $H$ and constant pitch $S$. It is observed from Fig.14 that, the friction factor $f_{c}$ decreases for all the geometries of depths $H$ with the increase of $R e_{c}$ at constant pitch of $S=5.2 \mathrm{~mm}$. for the same $R e_{c}$ of 9000, the friction factor $f_{c}$ is at depths of $H=1.15,1.1$ and $0.6 \mathrm{~mm}$ is higher than that of smooth tube value by $22.8 \%, 18.4 \%$ and $2.3 \%$, respectively. Owning to flow swirls increases along surfaces of the tube, this cause more turbulence in flow, this lead to increase the friction factor and pressure drop. The friction loss for be attributed to the block of flow passage, long residence time or flow path, and vortices flows, which results in higher local velocity, larger pressure drop and more contact area. 


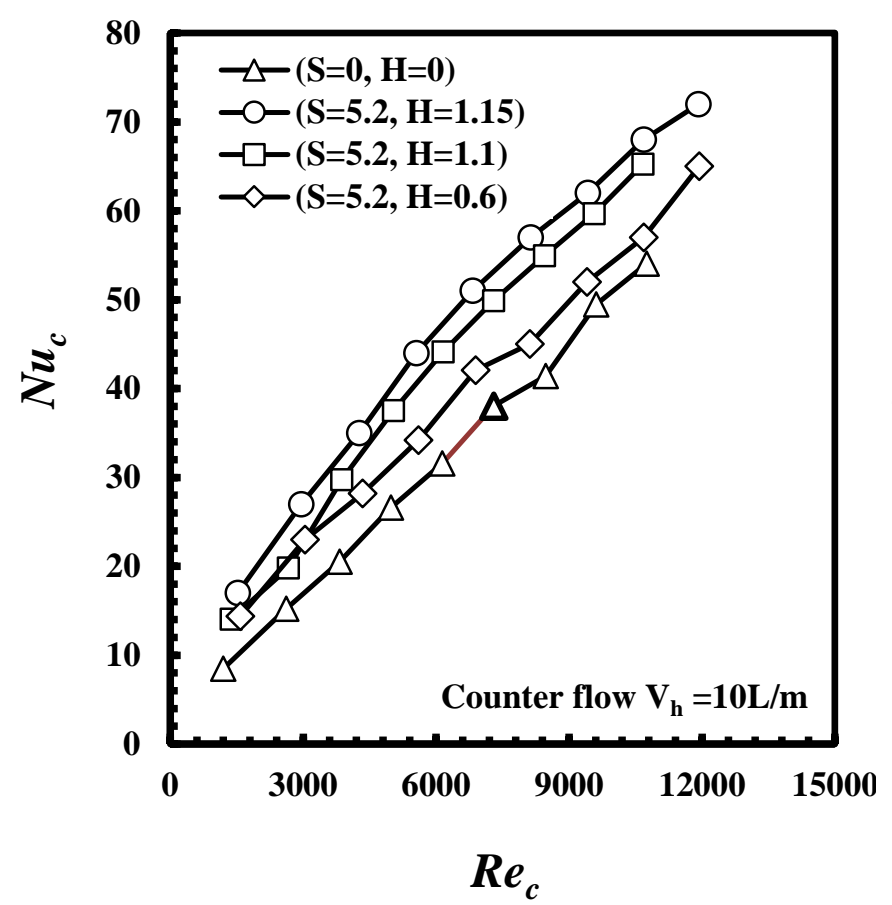

Fig.11.Variation of Nusselt Number with Reynolds Number of twisted spiral tube at different depths

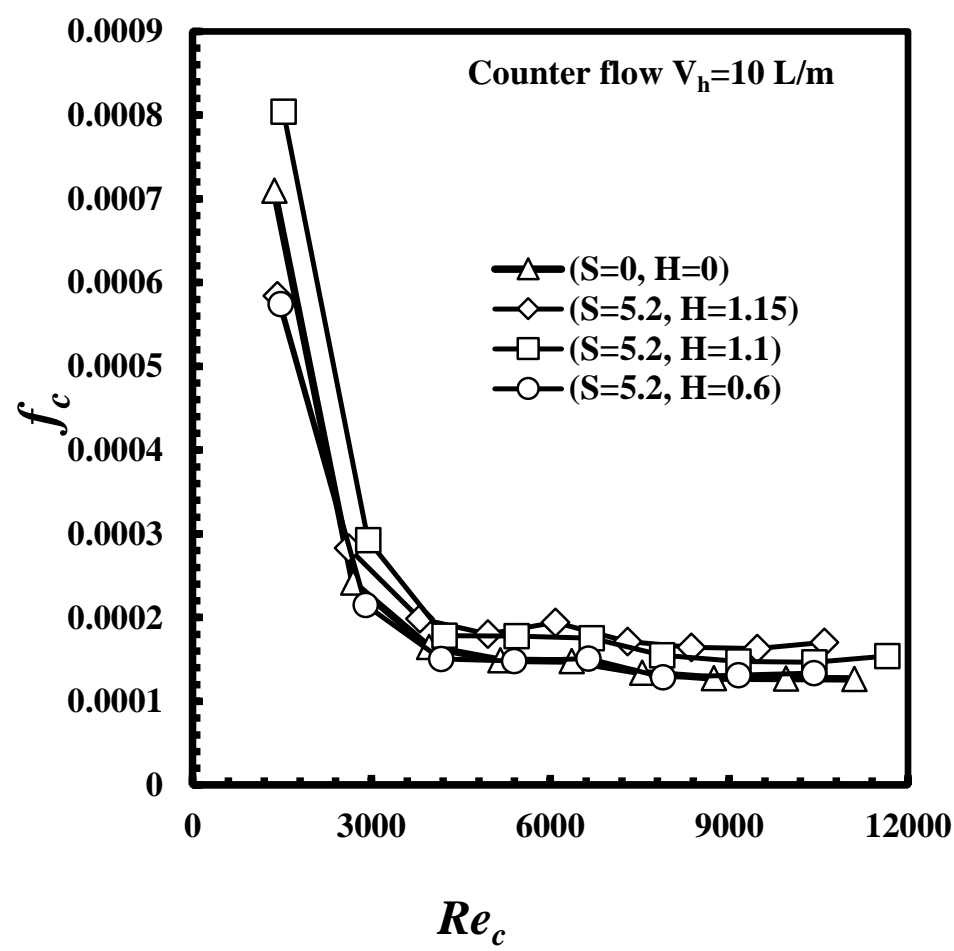

Fig.13.Variation of pressure drop, with Reynolds Number of twisted spiral tube at different depths

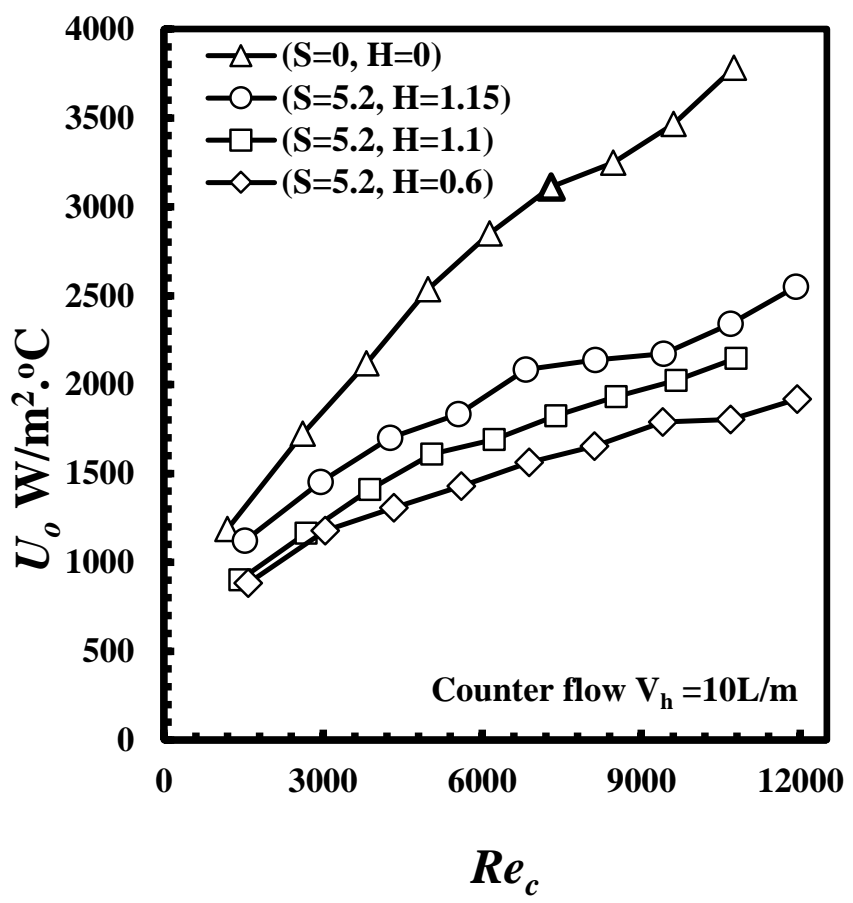

Fig.12.Variation of overall heat transfer coefficient with Reynolds Number of twisted spiral tube at different depths

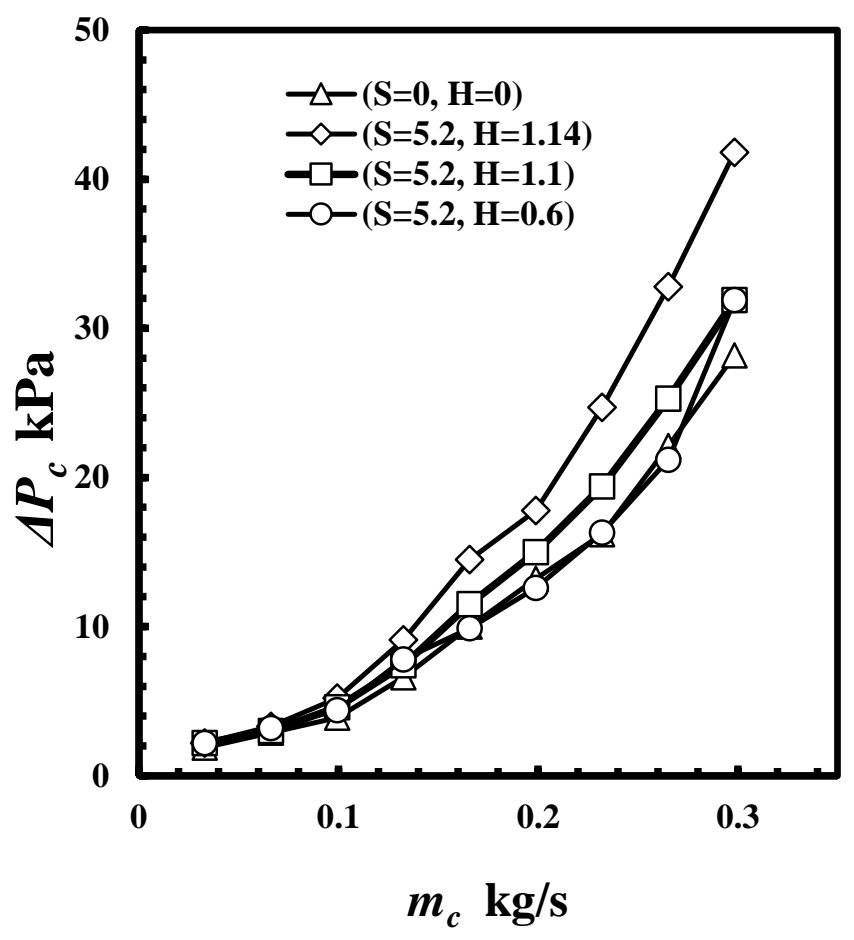

Fig.14.Variation of friction factor with Reynolds Number of twisted spiral tube at different depths 


\section{Conclusion.}

The present work investigates experimentally the heat transfer and pressure drop of a smooth and twisted spiral tube. The effects of the pitch $(S)$ and depth $(H)$ on the thermal performance of twisted spiral tube heat exchanger are investigated. The study focused on the thermo fluid characteristics of the flow of the double-smooth and twisted spiral tube. The friction factor, overall heat transfer coefficient, $N u$ and pressure drop were presented for all investigated parameters. The main conclusions were summarized as:

- The $N u_{c}$ in the twisted spiral tubes is increased in all cases of pitch $(S)$ above that of the smooth tube. The enhancement of $N u$ from twisted spiral tubes over that of the smooth tube by $33.6 \%$ at $S=3.9 \mathrm{~mm}$.

- The $N u$ in twisted spiral tubes is increased in all cases of depth $(H)$ above that of the smooth tube. The enhancement of $N u$ from twisted spiral tubes over that of the smooth tube ranged is $34.4 \%$ at $H=1.15 \mathrm{~mm}$.

- The friction factor in twisted spiral tubes is increased at twisted spiral pitches of 3.9, 5.2 and $8.2 \mathrm{~mm}$ above that of the smooth tube by $23.2 \%, 18.4 \%$ and $4.6 \%$, respectively.

- The $(f)$ in twisted spiral tubes is increased twisted spiral depths $(H)$ of $1.15,1.1$ and $0.6 \mathrm{~mm}$ above that of the smooth tube by $22.8 \%, 18.4 \%$ and $2.3 \%$, respectively.

- The Nusselt number of counter flow arrangement was higher than that of the parallel flow arrangement by $16 \%$ at the same operating condition.

\section{References}

[1] Z. S. Kareem, M.N. Mohd Jaafar, T. M. Lazim, S. Abdullah and A. F. Abdu WWahid ، Heat transfer enhancement in two-start spirally corrugated tube 'Alexandria Engineering Journal، 54 (2015) 415-422.

[2] H.H. Balla. Enhancement of heat transfer in six-start spirally corrugated tubes • Case Studies in Thermal Engineering ، 9 (2017) 79-89.

[3] X .Tang , X. Dai and D. Zhu' Experimental and numerical investigation of convective heat transfer and fluid flow in twisted spiral tuber International Journal of Heat and Mass Transfer ، 90 .(2015). 523-541.

[4] Z.S.Kareema , S. Abdullah, T.M.Lazim, M.N.M.Jaafar and A.F.AbdulWahid، Heat transfer enhancement in three-start spirally corrugated tube، Chemical Engineering Science ، 134 (2015) 746-757.

[5] Z. j.i. Jin, Fu .Chen, Z .x .Gao, X.f .Gao and J.yuan Qian ، Effects of pitch and 
corrugation depth on heat transfer characteristics in six-start spirally corrugated tube، International Journal of Heat and Mass Transfer، 108 (2017) 1011-1025.

[6] J.J. Liu, Z.C. Liu and W. Liu ، 3D numerical study on shell side heat transfer and flow characteristics of rod-baffle heat exchangers with spirally corrugated tubes' International Journal of Thermal Sciences ،89 (2015) 34-42.

[7] F. Xin, Z. Liu, N. Zheng, P. Liu and W. Liu ' Numerical study on flow characteristics and heat transfer enhancement of oscillatory flow in a spirally corrugated tube' International Journal of Heat and Mass Transfer ،127 (2018) 402-413.

[8] A. Kalendar,T. Galal, A. Al-Saftawi and M. Zedan' Enhanced tubing thermal performance for innovative MSF system، Journal of Mechanical Science and Technology, 25 (8) (2011) 1969-1977.

[9] S. Rozzi, R. Massini, G. Paciello, G. Pagliarini, S. Rainieri and A. Trifiro`‘ Heat treatment of fluid foods in a shell and tube heat exchanger: Comparison between smooth and helically corrugated wall tubes، Journal of Food Engineering ‘79.(2007).249-254.

[10] P. Poredo, T. Suklje, S.Medved and C.Arkar' An experimental heat-transfer study for a heat-recovery unit made of corrugated tubes • Applied Thermal Engineering ، 53 (2013) 4956.

[11] W. Xu, S. Wang, G.g Liu, Q. Zhang, M. Hassan and H. Lu، Experimental and numerical investigation on heat transfer of Therminol heat transfer fluid in an internally four-head ribbed tube، International Journal of Thermal Sciences ،116 (2017) 32-44.

[12] L. Jianfeng, S. Xiangyang, D. Jing and Y. Jianping، Transition and turbulent convective heat transfer of molten salt in spirally grooved tube، Experimental Thermal and Fluid Science ،47 (2013) 180-185.

[13] D. Khoeini, M.A. Akhavan-Behabadi and A. Saboonchi، Experimental study of condensation heat transfer of R-134aflow in corrugated tubes with different inclinations، International Communications in Heat and Mass Transfer ،39 (2012) 138-143.

[14] J.F.Seara and F. J. Uhi'a، Heat transfer and friction characteristics of spirally corrugated tubes for outer ammonia condensation، international journal of refrigeration، 35. (2012)2022-2032.

[15] S. Pethkool , S. Eiamsa-ard, S. Kwankaomeng and P. Promvonge، Turbulent heat transfer enhancement in a heat exchanger using helically corrugated tube، International Communications in Heat and Mass Transfer، 38 (2011) 340-347.

[16] J.P. Holman, Experimental Method for Engineers, Eighth ed., McGraw-Hill Book Company, New York, 2001, pp. 62-65.

[17] P. Naphon, M.Nuchjapo and Jutarat Kurujareon, Tube side heat transfer coefficient and friction factor characteristics of horizontal tubes with helical rib, Energy Conversion and Management, 47 (2006) 3031-3044. 